that their precepts, principles, and attitudes are as valid now as they were in 1832 . Hastings was a very great man and he was also a very modest man, but I have no doubt that he would have been quietly but justifiably satisfied with the achievements of his Association. I am equally sure, however, that he would have pointed out that the problems facing the medical profession and society continue and that the need for an active and vigorous BMA is just as great as it ever was.

No words can better express my feelings about the BMA than those spoken by a very close friend and ally of Charles Hastings, Dr John Connolly of Warwick. These were part of his address to the third annual meeting held in Birmingham, and his sentiment and his message are just as appropriate today as they were in January 1834 :

"We have no reason to apprehend that our successors will look back to the first proceedings of the Association with any feelings but those of respect; they will see that our regards, not narrowed to our own little day, were extended forward to their days, and to the hidden days beyond them. Animated by the same pure ambition as the founders, I trust they (us) will carry on medical knowledge beyond the point at which they themselves became engaged in its pursuit, and in their turn will cheerfully transmit it, by them increased, to other generations, by whom, with the permission of Providence, it may be more and more cultivated to the end of time."

The circumstances surrounding the foundation of the BMA are well recorded, and I have drawn freely on the standard histories by Little, McMenemey, ${ }^{3}$ and Vaughan. ${ }^{2}$

\section{References}

${ }^{1}$ Little EM. History of the British Medical Association 1832-1932. London: British Medical Association, 1932.

2 Vaughan P. Doctors' commons. London: Heinemann, 1959.

${ }^{3}$ McMenemey WH. The life and times of Sir Charles Hastings, founder of the British Medical Association. Edinburgh: Livingstone, 1959.

\title{
Miraculous deliverance of Anne Green: an Oxford case of resuscitation in the seventeenth century
}

\author{
J TREVOR HUGHES
}

On 14 December 1650 a remarkable event took place in Oxford, and of the contemporary accounts one is so detailed ${ }^{1}$ that it constitutes an important report of an early example of resuscitation of a person presumed dead. Anne Green was executed and then revived by the two doctors who were proposing to dissect her. The case is so bizarre that a full account is of interest.

Apart from the hangman and the justices of Oxford, whose actions today appear so brutish, the persons concerned in this dramatic episode are Anne Green herself, Dr William Petty (later Sir William Petty), and Dr Thomas Willis (later Sedleian Professor of Natural Philosophy in Oxford). The circumstances arose from the custom of granting the corpse of an executed criminal to the reader in anatomy in order that an anatomical dissection might be performed for the benefit of the Oxford students of medicine.

\section{Anatomical dissection in Oxford}

A few words about the practice of anatomical dissection in Oxford are appropriate. ${ }^{2}$ Until the middle of the sixteenth century, anatomical dissection of the human body was conducted in Oxford as in most European universities according to a ritual that had not been altered for centuries. The Hogarth caricature "The Reward of Cruelty," although engraved in the eighteenth century, depicts the mediaeval scene. The dissection of the cadaver is shown being performed by an assistant, while the professor sits on a raised throne above the dissection table and reads aloud from the works of either Galen or Mondino. In Oxford the anatomical dissections took place in the anatomy

Paper presented at the 12th World Congress of Neurology, Kyoto, Japan, September 1980 .

\footnotetext{
Department of Neuropathology, Radcliffe Infirmary, Oxford OX2 6HE

J TREVOR HUGHES, MD, FRCPATH, consultant neuropathologist
}

school, which was part of the university schools quadrangle and may be seen in Loggan's print of 1675.

In 1549, however, the statutes of the University of Oxford were revised after the visitation of King Edward VI, and this revision caused changes in the instruction of medicine. From this time the Oxford medical student was obliged to view two anatomical dissections and also to perform two dissections.

To obtain the human cadavers for these new requirements was a difficulty that was resolved in 1636 by a section of the great Charter of Charles I to the University of Oxford. This part of the charter permitted the anatomy reader to demand, for the purpose of anatomical dissection, the body of any person executed within 21 miles of Oxford. This was the statute invoked in the case of Anne Green in December 1650.

\section{Anne Green and her "crime"}

Anne Green was a maid employed by Sir Thomas Read who lived in a large house at Duns Tew in Oxfordshire. She was born at Steeple Barton and, at the time of this narrative, was 22 years of age. She was described as "of middle stature, strong, fleshy, and of an indifferent good feature." Apparently she was seduced by $\mathrm{Mr}$ Geoffrey Read, the grandchild of Sir Thomas Read, conceived, and subsequently gave precipitate delivery of a premature stillborn boy. The poor girl concealed the body of the child, and this body being subsequently discovered caused her to be suspected of murder. She was immediately taken into custody and taken before a justice of the peace who consigned her to the Oxford gaol where she remained for three weeks until the next sessions were held in Oxford. At the sessions she was arraigned, condemned to death, and on Saturday 14 December 1650 she was hanged.

\section{The execution}

The place of execution was the Cattle yard in Oxford. A psalm was sung and some mitigation was said of her crime with 
some pointed remarks against the family for whom she had worked and who had used her so ill. She was then executed in the customary way by being turned off the ladder to hang by the neck (figure). She hung for half an hour during which time

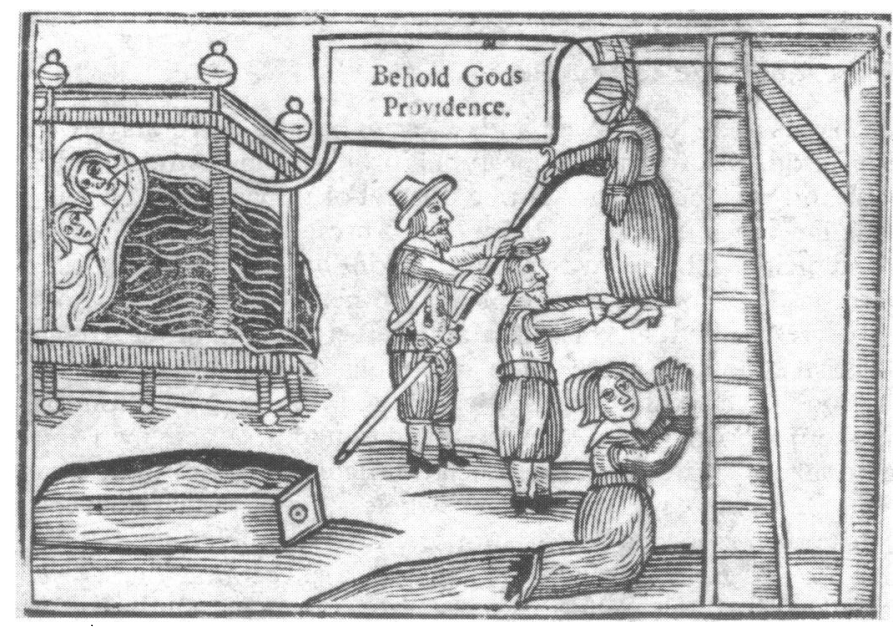

The execution and resuscitation of Anne Green. (By kind permission of the Bodleian Library, Oxford.)

some of her friends thumped her on the breast, "others hanging with all their weight upon her legs, sometimes lifting her up, and then pulling her down again with a sudden jerk, thereby the sooner to despatch her out of her pain." At this point the under sheriff required them to desist lest they should break the rope. When everyone thought she was dead, the body was taken down and put in a coffin and carried to the private house where lodged Dr William Petty, the reader in anatomy.

\section{The resuscitation}

When the coffin was opened, Anne Green was observed to make a breath and a rattle was heard in her throat. William Petty and Thomas Willis abandoned all thoughts of a dissection and proceeded to revive their patient. They caused her to be held up in the coffin and then by wrenching open her teeth they poured in her mouth some hot cordial which caused her more coughing. They then rubbed and chafed her fingers, hands, arms, and feet, and, after a quarter of an hour of this with more cordial into her mouth and the tickling of her throat with a feather, she opened her eyes momentarily. At this stage the doctors opened a vein and bled her of five ounces of blood. They then continued administering the cordial and rubbing her arms and legs. Ligatures, presumably compressing bandages, were applied to her arms and legs. Heating plasters were put to her chest and another apparently inserted as an enema, "ordered an heating odoriferous Clyster to be cast up in her body, to give heat and warmth to her bowels." They then placed her in a warm bed with another woman to lie with her (see figure) and keep her warm. This seventeenth-century account includes excellent observations on the recovery of the patient. After 12 hours she began to speak and 24 hours after her revival she was answering questions freely. At two days her memory was normal apart from the period of the execution and the resuscitation. At four days she was eating solid food, and one month after the event she was fully recovered except for the period of amnesia that had been noted at two weeks to shorten somewhat.

It is most instructive to consider the methods that these early physicians used to monitor the progress of their patient. There were frequent observations of the state of the pulse. Her colour was observed closely and soon after her revival her face was noted to be sweating, swelling, and very red, particularly near the place where the knot of the rope had been fastened. There were frequent tests of her sight and her hearing and also of her understanding of questions. Even when she was mute, she was asked to move her hand or open an eye if she could hear the question. Her memory was frequently tested by specific questions. The description was made, when her memory returned after two days, that "her memory was like a clock whose weights had been taken off a while and afterwards hung on again." At two weeks there was the interesting observation of the slight return of her memory of the execution. She remembered "a fellow in a blanket" who could only have been the executioner in his cloak. After two weeks her memory of the event remained static. Other contemporary accounts-there were so many, including a great deal of verse, that possibly the event was given as an essay subject to the students-described the great visions that Anne Green saw of the afterlife. The description cited here, however, appears quite factual and completely in accord with a modern case report.

\section{Further career of Anne Green}

The subsequent history of Anne Green is interesting. The Under Sheriff of Oxford solicited the governor of the Oxford gaol and the justices of the peace for her reprieve. The justices decided that the hand of God had preserved her, and they wished to co-operate with divine providence in granting her a reprieve pending the time that a pardon might be obtained, and this pardon was subsequently granted. Many people in Oxford had seen her during her recovery, and it seems that her father charged for admission. This collection and a subsequent financial appeal on her behalf produced many pounds, which paid the bill of the apothecary, her food and lodging, and the legal expenses of her pardon. Anne Green's fame continued after her full recovery, when she returned to some friends in the country taking with her the coffin in which she had lain. She then married, bore three children, and lived for 15 years after her famous execution and resuscitation. William Petty and Thomas Willis also achieved considerable fame from their conduct of the case. Petty left the practice of medicine shortly after but Willis went on to become an Oxford professor and then a wealthy London physician.

\section{References}

${ }^{1}$ Newes from the Dead or $A$ True and Exact Narration of the miraculous deliverance of Anne Green. Written by a Scholler in Oxford. Oxford: Printed by Leonard Lichfield for Tho Robinson, 1651.

2 Sinclair HM, Robb-Smith AHT. A short history of anatomical teaching in Oxford. Oxford: Oxford University Press, 1950. 